\title{
Susceptibility of Enterococcus faecalis and Propionibacterium acnes to antimicrobial photodynamic therapy
}

\author{
Sarah Raquel de Annunzio ${ }^{\mathrm{a}, 1}$, Laura Marise de Freitas ${ }^{\mathrm{a}, 1}$, Ana Lígia Blanco ${ }^{\mathrm{a}}$, \\ Mardoqueu Martins da Costa ${ }^{\mathrm{b}}$, Christian C. Carmona-Vargas ${ }^{\mathrm{c}}$, Kleber Thiago de Oliveira ${ }^{\mathrm{c}}$, \\ Carla Raquel Fontana ${ }^{\mathrm{a}, *}$
}

\author{
a Universidade Estadual Paulista (Unesp), Faculdade de Ciências Farmacêuticas, Araraquara. Rodovia Araraquara-Jaú, Km1, Campus Ville, Araraquara, SP, CEP 14800- \\ 903, Brazil \\ ${ }^{\mathrm{b}}$ Universidade Brasil (UniBrasil), Departamento de Engenharia Biomédica, Rua Carolina Fonseca, 235, Vila Santana, São Paulo, SP CEP: 08230-030, Brazil \\ ${ }^{\mathrm{c}}$ Universidade Federal de São Carlos (UFSCar), Departamento de Química, Laboratório de Química Bioorgânica, Rodovia Washington Luis, Km 235 - SP-310, São Carlos, \\ SP, CEP 13565-905, Brazil
}

\section{A R T I C L E I N F O}

\section{Keywords:}

Antimicrobial photodynamic therapy

Enterococcus faecalis

Propionibacterium acnes

Methylene blue

Chlorin-e6

Curcumin

\begin{abstract}
A B S T R A C T
Bacterial resistance to available antibiotics nowadays is a global threat leading researchers around the world to study new treatment modalities for infections. Antimicrobial photodynamic therapy (aPDT) has been considered an effective and promising therapeutic alternative in this scenario. Briefly, this therapy is based on the activation of a non-toxic photosensitizing agent, known as photosensitizer (PS), by light at a specific wavelength generating cytotoxic singlet oxygen and free radicals. Virtually all studies related to aPDT involve a huge screening to identify ideal PS concentration and light dose combinations, a laborious and time-consuming process that is hardly disclosed in the literature. Herein, we describe an antimicrobial Photodynamic Therapy (aPDT) study against Enterococcus faecalis and Propionibacterium acnes employing methylene blue, chlorin-e6 or curcumin as PS. Similarities and discrepancies between the two bacterial species were pointed out in an attempt to speed up and facilitate futures studies against those clinical relevant strains. Susceptibility tests were performed by the broth microdilution method. Our results demonstrate that aPDT mediated by the three above-mentioned PS was effective in eliminating both gram-positive bacteria, although $P$. acnes showed remarkably higher susceptibility to aPDT when compared to $E$. faecalis. PS uptake assays revealed that $P$. acnes is 80 times more efficient than $E$. faecalis in internalizing all three PS molecules. Our results evidence that the cell wall structure is not a limiting feature when predicting bacterial susceptibility to aPDT treatment.
\end{abstract}

\section{Introduction}

Bacterial resistance to available antibiotics and the low perspective related to the discovery of new drugs have lead researchers to search for alternative antimicrobial treatment [1], and photodynamic therapy (PDT) is among the alternatives. PDT is a treatment modality based on the interaction of three fundamental components: a photosensitizer (PS), visible light and oxygen $[2,3]$. When the PS is excited by the light it can interact with the surroundings through two pathways, named type I and type II reactions. Type I reaction takes place when the PS in its excited triplet state transfers charges $\left(\mathrm{e}^{-}\right.$or $\left.\mathrm{H}^{+}\right)$to biomolecules, to originate radical species. In the type II reaction, the triplet excited state PS transfers energy directly to the ground-state triplet oxygen, in a phenomenon named triplet-triplet annihilation, leading to the formation of the highly reactive and cytotoxic singlet oxygen. Both reactions take place at the same time and the relation between the two processes depends on the PS, the oxygen and substrates concentrations, and the bond-affinity of PS with the substrates [4-7].

Photosensitizers are molecules that possess the ability to absorb light in specific wavelengths and use the energy to trigger photo-oxidative reactions in the presence of molecular oxygen [2,8]. An efficient PS must present no toxicity in the absence of light activation, selective uptake by the target cell, and generate high amounts of reactive oxygen species (ROS), among other properties [9]. In the past few years, different PSs have been studied in PDT. Curcumin (CUR), methylene blue (MB), and chlorin-e6 (Ce6) are examples of molecules with well-established photosensitizing properties, which are being widely employed in studies involving this treatment modality [10-14], and were the PS

\footnotetext{
* Corresponding author.

E-mail addresses: mardoqueu.costa@universidadebrasil.edu.br (M.M. da Costa), kleber.oliveira@ufscar.br (K.T. de Oliveira), fontanacr@fcfar.unesp.br (C.R. Fontana).

${ }^{1}$ These authors contributed equally to this work.
} 


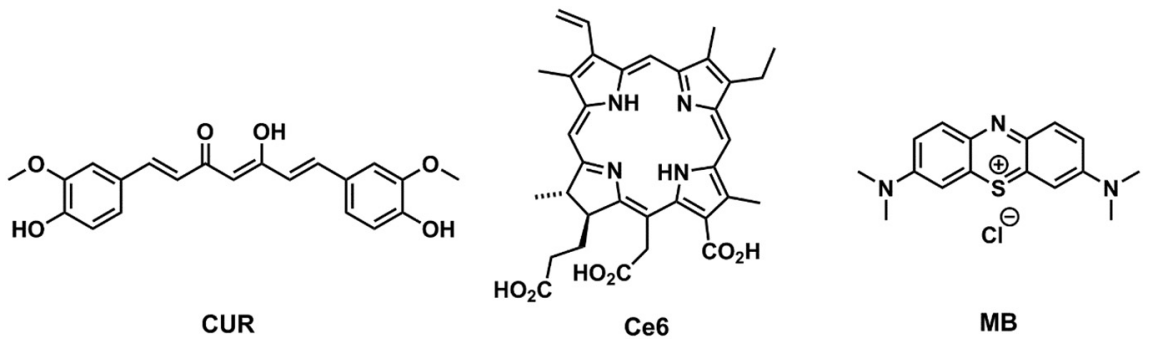

Fig. 1. Chemical structures of the photosensitizers. CUR: curcumin; Ce6: chlorin-e6; MB: methylene blue. (For interpretation of the references to colour in this figure legend, the reader is referred to the web version of this article.) used in this study.

The three PS were chosen for their distinct chemical properties (Fig. 1), allowing us to evaluate if the aPDT effects would present some level of selectivity regarding the PS molecule. Curcumin, for example, is a phenolic natural product that can be synthetically obtained or extracted from the rhizomes of Curcuma longa. This natural PS is a medium-water insoluble molecule and presents an absorption band mostly in the blue region, with a peak at $430 \mathrm{~nm}$ [15-17]. Interestingly, the fast photobleaching of CUR allows the treatment of local lesions and infections with no persistent photosensitizing activity after a few hours, making this PS very strategic.

Methylene blue, by its turn, is a low-cost phenothiazine derivative, well-soluble in water and ethanol, with a maximum absorption at $664 \mathrm{~nm}$, a wavelength with good tissue penetration, which enables the application of MB to treat deeper lesions $[18,19]$. Finally, chlorin-e6 belongs to the class of chlorophyll derivatives, with its tetrapyrrole ring conferring it hydrophobic and hydrophilic (amphiphilic) features; it absorbs light in both 400 and $660 \mathrm{~nm}$ and produces high amounts of singlet oxygen, both in vitro and in vivo [20-22]. Structurally related to PDZ $^{\circledast}$ (Photoditazine), Ce6 has been presenting better PDT activities due to its amphiphilicity and absence of dark toxicity [23] and is considered as a very promising candidate for systemic and non-systemic treatments. In summary, our study covered different classes of PS with different chemical and photochemical properties.

Numerous studies suggest that Gram-positive bacteria are more sensitive to aPDT than Gram-negative, due to the differences in their cell wall structure. Gram-positives present a thick peptidoglycan layer over the plasmatic membrane, which confers them a relatively more porous cell wall, allowing for the PS to diffuse easily to the cell interior. Gram-negatives, on the other hand, have a highly selective external membrane, a thin peptidoglycan layer, and the plasmatic membrane, making the PS permeation more difficult [24-27].

However, studies have demonstrated that the parameters used to determine the bacterial susceptibility to aPDT, such as light dose and PS concentration, can vary independently of the cell wall structure, with discrepant differences of parameters and response to the therapy found among bacteria of the same coloration group, evidencing that the cellular structure is not the limiting factor for the success of the therapy [28-30]. Propionibacterium acnes and Enterococcus faecalis, for instance, are both Gram-positive non-spore forming facultative anaerobes [31] whose susceptibility to aPDT have been demonstrated to be remarkably different, considering the same PS, in studies of our group. This finding suggests a more complex mechanism of susceptibility than just the cell wall structure, given that both species present the same basic assembly.

After several studies with both species conducted by our group, we observed a huge necessity to adapt the initial aPDT screening for PS concentration and light dose combinations for each one, even though they are both gram-positive. In general, data obtained from aPDT screenings are not disclosed in publications, having the sole purpose of providing ground information for other assays. This pattern of disclosing, however, implies that every new study has to initiate a new screening until determining the ideal combinations of PS concentration and light dose. Therefore, one of the aims of the present study was to provide basic parameters to facilitate future studies with those strains, as well as to investigate the mechanisms behind the difference in behavior observed for the two species.

\section{Material and Methods}

\subsection{Bacterial Strains and Culture Conditions}

The strains used in this study were Enterococcus faecalis (ATCC ${ }^{\circledR}$ $29,212^{\mathrm{TM}}$ ) and Propionibacterium acnes (ATCC ${ }^{\circledR} 6919^{\mathrm{TM}}$ ), both obtained from the National Institute of Quality Control in Health (INCQS) from the Oswaldo Cruz Foundation (FIOCRUZ - Manguinhos, RJ, Brazil). E. faecalis was cultured in blood agar (defibrinated sheep blood 5\%; BHI $2,6 \%$; TSA $2 \%$; yeast extract $1 \%$ ) in an anaerobic jar at $37{ }^{\circ} \mathrm{C}$; P. acnes was incubated under the same conditions, but in Reinforced Clostridial Agar (Himedia - Mumbai, India). Strains were cultured in solid media and isolated colonies were suspended in TSB (Kasvi - Curitiba, PR, Brazil; P. acnes) or BHI broth (Kasvi - Curitiba, PR, Brazil; E. faecalis) to prepare the inocula prior to each assay. Inocula were adjusted by spectrophotometer (Biotek ${ }^{\circledast}$ ELx800 - Winooski, VT, USA) reading at $630 \mathrm{~nm}$ to yield an initial suspension of $\sim 5 \times 10^{9} \mathrm{cell} / \mathrm{mL}$.

\subsection{Photosensitizers and Light Sources}

Chlorin-e6 (Ce6) and curcumin (CUR) were synthesized as described in the literature [32-34]. Methylene blue (MB) was obtained from Sigma (Sigma-Aldrich Co. LLC, St. Louis, MO, USA). All three photosensitizers' solutions were prepared in an environment protected from light. A stock solution of methylene blue was prepared in deionized water and diluted to working concentrations in broth; curcumin's stock solution was prepared in $100 \%$ DMSO and diluted in $0.5 \%$ sucrose to achieve working concentrations; chlorin-e6 was solubilized in $10 \%$ DMSO to give stock solutions, and diluted to working concentrations in broth. Work solutions were always prepared immediately prior to the beginning of the assays.

Light sources consisted of 48 LEDs with variable intensities assembled as a compact illumination system with a homogeneous illumination area and a cooling system to avoid overheating (IrradLED ${ }^{\circledR}-$ biopdi, Sao Carlos, SP, Brazil). Curcumin was activated by light at $450 \mathrm{~nm}\left(151 \mathrm{~mW} / \mathrm{cm}^{2}\right)$; methylene blue and chlorin-e6 were activated by light at $660 \mathrm{~nm}\left(153 \mathrm{~mW} / \mathrm{cm}^{2}\right)$. The distance between the LEDs and the plate allowed an even distribution of light on each well, and light was delivered from underneath the plates.

\subsection{Photodynamic Therapy}

Susceptibility test was performed by the broth microdilution technique, employing a 96 wells plate. PS solutions were prepared with twice the desired work concentration, in triplicates, to a final volume of $50 \mu \mathrm{L} /$ well. Bacterial suspensions were prepared in $3 \mathrm{~mL}$ of broth (BHI for $E$. faecalis, TSB for $P$. acnes), their optical density was measured at $630 \mathrm{~nm}\left(\mathrm{OD}_{630}\right.$ between 0.08 and 0.1$)$ and $50 \mu \mathrm{L}$ aliquots were added to each well already containing a PS solution or $50 \mu \mathrm{L}$ of broth (growth control). The addition of the suspensions to the wells resulted in a $50 \%$ dilution of both the inocula and the solutions. Bacterial suspensions 
Table 1

- chlorin-e6-mediated aPDT.

\begin{tabular}{|c|c|c|c|c|c|}
\hline Strain & Chlorin-E6 concentration & Light dose & Average $\log _{10}$ of $\mathrm{CFU} / \mathrm{mL}(\mathrm{SD})$ & $\log _{10}$ reduction ${ }^{\mathrm{a}}$ & $\%$ reduction $^{\mathrm{a}}$ \\
\hline \multirow[t]{20}{*}{ Enterococcus faecalis } & \multirow[t]{4}{*}{$21 \mu \mathrm{M}$} & $30 \mathrm{~J} / \mathrm{cm}^{2}$ & $9.56(0.56)$ & 0.64 & 61.67 \\
\hline & & $45 \mathrm{~J} / \mathrm{cm}^{2}$ & $9.26(0.08)$ & 0.93 & 86.79 \\
\hline & & $60 \mathrm{~J} / \mathrm{cm}^{2}$ & $8.84(0.08)$ & 1.36 & 95.00 \\
\hline & & $90 \mathrm{~J} / \mathrm{cm}^{2}$ & $8.66(1.14)$ & 1.54 & 97.00 \\
\hline & \multirow[t]{4}{*}{$42 \mu \mathrm{M}$} & $30 \mathrm{~J} / \mathrm{cm}^{2}$ & $9.70(0.46)$ & 0.50 & 51.90 \\
\hline & & $45 \mathrm{~J} / \mathrm{cm}^{2}$ & $8.39(0.07)$ & 1.81 & 98.21 \\
\hline & & $60 \mathrm{~J} / \mathrm{cm}^{2}$ & $0.00(0.00)$ & 10.20 & 100 \\
\hline & & $90 \mathrm{~J} / \mathrm{cm}^{2}$ & $0.00(0.00)$ & 10.20 & 100 \\
\hline & \multirow[t]{4}{*}{$84 \mu \mathrm{M}$} & $30 \mathrm{~J} / \mathrm{cm}^{2}$ & $9.47(0.86)$ & 0.73 & 55.00 \\
\hline & & $45 \mathrm{~J} / \mathrm{cm}^{2}$ & $0.00(0.00)$ & 10.20 & 100 \\
\hline & & $60 \mathrm{~J} / \mathrm{cm}^{2}$ & $0.00(0.00)$ & 10.20 & 100 \\
\hline & & $90 \mathrm{~J} / \mathrm{cm}^{2}$ & $0.00(0.00)$ & 10.20 & 100 \\
\hline & \multirow[t]{4}{*}{$126 \mu \mathrm{M}$} & $30 \mathrm{~J} / \mathrm{cm}^{2}$ & $9.73(0.24)$ & 0.47 & 58.57 \\
\hline & & $45 \mathrm{~J} / \mathrm{cm}^{2}$ & $0.00(0.00)$ & 10.20 & 100 \\
\hline & & $60 \mathrm{~J} / \mathrm{cm}^{2}$ & $0.00(0.00)$ & 10.20 & 100 \\
\hline & & $90 \mathrm{~J} / \mathrm{cm}^{2}$ & $0.00(0.00)$ & 10.20 & 100 \\
\hline & \multirow[t]{4}{*}{$168 \mu \mathrm{M}$} & $30 \mathrm{~J} / \mathrm{cm}^{2}$ & $9.51(0.66)$ & 0.69 & 61.79 \\
\hline & & $45 \mathrm{~J} / \mathrm{cm}^{2}$ & $0.00(0.00)$ & 10.20 & 100 \\
\hline & & $60 \mathrm{~J} / \mathrm{cm}^{2}$ & $0.00(0.00)$ & 10.20 & 100 \\
\hline & & $90 \mathrm{~J} / \mathrm{cm}^{2}$ & $0.00(0.00)$ & 10.20 & 100 \\
\hline \multirow[t]{15}{*}{ Propionibacterium acnes } & \multirow[t]{3}{*}{$2.62 \mu \mathrm{M}$} & $3.25 \mathrm{~J} / \mathrm{cm}^{2}$ & $0.00(0.00)$ & 8.20 & 100 \\
\hline & & $7.5 \mathrm{~J} / \mathrm{cm}^{2}$ & $0.00(0.00)$ & 8.20 & 100 \\
\hline & & $15 \mathrm{~J} / \mathrm{cm}^{2}$ & $0.00(0.00)$ & 8.20 & 100 \\
\hline & \multirow[t]{3}{*}{$5.25 \mu \mathrm{M}$} & $3.25 \mathrm{~J} / \mathrm{cm}^{2}$ & $0.00(0.00)$ & 8.20 & 100 \\
\hline & & $7.5 \mathrm{~J} / \mathrm{cm}^{2}$ & $0.00(0.00)$ & 8.20 & 100 \\
\hline & & $15 \mathrm{~J} / \mathrm{cm}^{2}$ & $0.00(0.00)$ & 8.20 & 100 \\
\hline & \multirow[t]{3}{*}{$10.5 \mu \mathrm{M}$} & $3.25 \mathrm{~J} / \mathrm{cm}^{2}$ & $0.00(0.00)$ & 8.20 & 100 \\
\hline & & $7.5 \mathrm{~J} / \mathrm{cm}^{2}$ & $0.00(0.00)$ & 8.20 & 100 \\
\hline & & $15 \mathrm{~J} / \mathrm{cm}^{2}$ & $0.00(0.00)$ & 8.20 & 100 \\
\hline & \multirow[t]{3}{*}{$21 \mu \mathrm{M}$} & $3.25 \mathrm{~J} / \mathrm{cm}^{2}$ & $0.00(0.00)$ & 8.20 & 100 \\
\hline & & $7.5 \mathrm{~J} / \mathrm{cm}^{2}$ & $0.00(0.00)$ & 8.20 & 100 \\
\hline & & $15 \mathrm{~J} / \mathrm{cm}^{2}$ & $0.00(0.00)$ & 8.20 & 100 \\
\hline & \multirow[t]{3}{*}{$42 \mu \mathrm{M}$} & $3.25 \mathrm{~J} / \mathrm{cm}^{2}$ & $0.00(0.00)$ & 8.20 & 100 \\
\hline & & $7.5 \mathrm{~J} / \mathrm{cm}^{2}$ & $0.00(0.00)$ & 8.20 & 100 \\
\hline & & $15 \mathrm{~J} / \mathrm{cm}^{2}$ & $0.00(0.00)$ & 8.20 & 100 \\
\hline
\end{tabular}

${ }^{\text {a }}$ Compared to control.

were incubated with the PS for 5 (curcumin and methylene blue) or 10 min (chlorin-e6) prior to plate irradiation with the appropriate light dose. After treatment, suspensions were submitted to 10 -fold serial dilutions until reaching $\sim 10^{3}$ cell $/ \mathrm{mL}$ ( $P$. acnes) or $\sim 10^{1}$ cell $/ \mathrm{mL}$ ( $E$. faecalis), and $5 \mu \mathrm{L}$ of each suspension was plated. The number of grown colonies was accessed after 2 days of growth at $37^{\circ} \mathrm{C}$ in an anaerobic jar.

\subsection{Photosensitizer Uptake}

Bacterial suspensions $\left(\sim 10^{8}\right.$ cells $\left./ \mathrm{mL}\right)$ were incubated in BHI or TSB broth at room temperature in the dark for $5 \mathrm{~min}$ with the photosensitizer in the following concentrations: Ce6-21 and $42 \mu \mathrm{M}$; CUR - 17 and $34 \mu \mathrm{M} ; \mathrm{MB}-39$ and $78 \mu \mathrm{M}$. Controls comprised of suspensions incubated with broth only. All groups were assayed in triplicates, on three different occasions. After incubation, cell suspensions were centrifuged ( $6500 \mathrm{rpm}$ for $5 \mathrm{~min}$ ), the supernatant was discarded, and bacteria were washed twice with $1 \mathrm{~mL}$ of sterile phosphate buffer (0.1 M, pH 7.4), and centrifuged again. The resulting bacterial pellet was dissolved in $2 \mathrm{~mL}$ of $0.1 \mathrm{M} \mathrm{NaOH}-1 \%$ sodium dodecyl sulfate (SDS) for 24 hate room temperature for cell digestion. The extracts had their endpoint fluorescence read in a spectrofluorometer (Synergy H1 MultiMode Reader, BioTek, Winooski, VT, USA). For MB, the excitation wavelength was $660 \mathrm{~nm}$ and the emission was $690 \mathrm{~nm}$; for Ce6, excitation was $500 \mathrm{~nm}$ and emission was $670 \mathrm{~nm}$; for CUR, excitation was $450 \mathrm{~nm}$ and emission was $640 \mathrm{~nm}$. PS dissolved in NaOH-SDS in several concentrations were used to make calibration curves, which were used for determination of PS concentration in the extract. PS concentration uptaken was correct by the cell number.

\subsection{Statistical Analysis}

Data were expressed as the mean plus standard deviation (SD) and were analyzed by one-way ANOVA with Tukey's post hoc test, using GraphPad Prism ${ }^{\circledR}$ Version 5.01 software (GraphPad Software Inc., La Jolla, CA, USA). Differences were considered to be significant when $p<0.05$ (confidence level of 95\%) and the maximum acceptable coefficient of variation was $25 \%$.

\section{Results}

\section{1. aPDT Susceptibility}

A screening comprising several PS concentrations versus energy fluences was conducted for both strains. Tables 1, 2 and 3 summarize the results. By analyzing the results of aPDT with chlorin-e6 (Ce6; Table 1 ) it is evident that $P$. acnes is extensively more susceptible to the treatment than $E$. faecalis. The minimum light dose applied to $E$. faecalis was $30 \mathrm{~J} / \mathrm{cm}^{2}$, which resulted in a maximum bacterium reduction of $61.8 \%$ ( $<1 \log _{10}$ of $\mathrm{CFU} / \mathrm{mL}$ ) when employing $168 \mu \mathrm{M}$ of Ce6. By applying a roughly 10 -fold lower energy fluence to $P$. acnes $(3.25 \mathrm{~J} /$ $\mathrm{cm}^{2}$ ), however, complete bacterial elimination was achieved with $2.62 \mu \mathrm{M}$ of Ce6. In comparison, the minimum Ce6 concentration to result in total $E$. faecalis reduction was $42 \mu \mathrm{M}$ irradiated with $60 \mathrm{~J} / \mathrm{cm}^{2}$.

The results obtained from aPDT with curcumin (Table 2) were very similar to the ones described for Ce6, with $P$. acnes presenting higher susceptibility to the therapy compared to $E$. faecalis. By employing $12.5 \mathrm{~J} / \mathrm{cm}^{2}$, only $14 \mu \mathrm{M}$ of curcumin was necessary to completely eliminate $P$. acnes, whereas the same result for $E$. faecalis required $136 \mu \mathrm{M}$ of the photosensitizer. In fact, as for Ce6, all curcumin versus 
Table 2

- curcumin-mediated aPDT.

\begin{tabular}{|c|c|c|c|c|c|}
\hline Strain & Curcumin concentration & Light dose & Average $\log _{10}$ of $\mathrm{CFU} / \mathrm{mL}(\mathrm{SD})$ & $\log _{10}$ reduction ${ }^{\mathrm{a}}$ & $\%$ reduction $^{\mathrm{a}}$ \\
\hline \multirow[t]{12}{*}{ Enterococcus faecalis } & \multirow[t]{3}{*}{$17 \mu \mathrm{M}$} & $12.5 \mathrm{~J} / \mathrm{cm}^{2}$ & $10.12(0.27)$ & 0.20 & 33.24 \\
\hline & & $18.75 \mathrm{~J} / \mathrm{cm}^{2}$ & $10.14(0.19)$ & 0.18 & 36.69 \\
\hline & & $25 \mathrm{~J} / \mathrm{cm}^{2}$ & $10.15(0.14)$ & 0.16 & 36.03 \\
\hline & \multirow[t]{3}{*}{$34 \mu \mathrm{M}$} & $12.5 \mathrm{~J} / \mathrm{cm}^{2}$ & $10.10(0.41)$ & 0.22 & 36.56 \\
\hline & & $18.75 \mathrm{~J} / \mathrm{cm}^{2}$ & $10.02(0.29)$ & 0.29 & 48.38 \\
\hline & & $25 \mathrm{~J} / \mathrm{cm}^{2}$ & $9.74(0.51)$ & 0.57 & 68.53 \\
\hline & \multirow[t]{3}{*}{$68 \mu \mathrm{M}$} & $12.5 \mathrm{~J} / \mathrm{cm}^{2}$ & $10.08(0.03)$ & 0.23 & 46.40 \\
\hline & & $18.75 \mathrm{~J} / \mathrm{cm}^{2}$ & $9.23(0.66)$ & 1.08 & 84.89 \\
\hline & & $25 \mathrm{~J} / \mathrm{cm}^{2}$ & $0.00(0.00)$ & 10.32 & 100 \\
\hline & \multirow[t]{3}{*}{$136 \mu \mathrm{M}$} & $12.5 \mathrm{~J} / \mathrm{cm}^{2}$ & $0.00(0.00)$ & 10.32 & 100 \\
\hline & & $18.75 \mathrm{~J} / \mathrm{cm}^{2}$ & $0.00(0.00)$ & 10.32 & 100 \\
\hline & & $25 \mathrm{~J} / \mathrm{cm}^{2}$ & $0.00(0.00)$ & 10.32 & 100 \\
\hline \multirow[t]{9}{*}{ Propionibacterium acnes } & \multirow[t]{3}{*}{$14 \mu \mathrm{M}$} & $3.12 \mathrm{~J} / \mathrm{cm}^{2}$ & $0.00(0.00)$ & 8.45 & 100 \\
\hline & & $6.25 \mathrm{~J} / \mathrm{cm}^{2}$ & $0.00(0.00)$ & 8.45 & 100 \\
\hline & & $12.5 \mathrm{~J} / \mathrm{cm}^{2}$ & $0.00(0.00)$ & 8.45 & 100 \\
\hline & \multirow[t]{3}{*}{$27 \mu \mathrm{M}$} & $3.12 \mathrm{~J} / \mathrm{cm}^{2}$ & $0.00(0.00)$ & 8.45 & 100 \\
\hline & & $6.25 \mathrm{~J} / \mathrm{cm}^{2}$ & $0.00(0.00)$ & 8.45 & 100 \\
\hline & & $12.5 \mathrm{~J} / \mathrm{cm}^{2}$ & $0.00(0.00)$ & 8.45 & 100 \\
\hline & \multirow[t]{3}{*}{$54 \mu \mathrm{M}$} & $3.12 \mathrm{~J} / \mathrm{cm}^{2}$ & $0.00(0.00)$ & 8.45 & 100 \\
\hline & & $6.25 \mathrm{~J} / \mathrm{cm}^{2}$ & $0.00(0.00)$ & 8.45 & 100 \\
\hline & & $12.5 \mathrm{~J} / \mathrm{cm}^{2}$ & $0.00(0.00)$ & 8.45 & 100 \\
\hline
\end{tabular}

${ }^{\text {a }}$ Compared to control.

Table 3

- methylene blue-mediated aPDT.

\begin{tabular}{|c|c|c|c|c|c|}
\hline Strain & Methylene blue concentration & Light dose & Average $\log _{10}$ of $\mathrm{cfu} / \mathrm{ml}$ (sd) & $\log _{10}$ reduction ${ }^{\mathrm{a}}$ & $\%$ reduction $^{\mathrm{a}}$ \\
\hline \multirow[t]{12}{*}{ Enterococcus faecalis } & \multirow[t]{3}{*}{$39 \mu \mathrm{M}$} & $30 \mathrm{~J} / \mathrm{cm}^{2}$ & $9.84(0.03)$ & 0.15 & 29.05 \\
\hline & & $60 \mathrm{~J} / \mathrm{cm}^{2}$ & $9.96(0.17)$ & 0.03 & 27.97 \\
\hline & & $90 \mathrm{~J} / \mathrm{cm}^{2}$ & $9.96(0.67)$ & 0.02 & 57.91 \\
\hline & \multirow[t]{3}{*}{$78 \mu \mathrm{M}$} & $30 \mathrm{~J} / \mathrm{cm}^{2}$ & $9.98(0.15)$ & 0.01 & 23.96 \\
\hline & & $60 \mathrm{~J} / \mathrm{cm}^{2}$ & $9.69(0.09)$ & 0.30 & 49.44 \\
\hline & & $90 \mathrm{~J} / \mathrm{cm}^{2}$ & $9.35(0.04)$ & 0.63 & 76.58 \\
\hline & \multirow[t]{3}{*}{$156 \mu \mathrm{M}$} & $30 \mathrm{~J} / \mathrm{cm}^{2}$ & $9.88(0.10)$ & 0.11 & 21.49 \\
\hline & & $60 \mathrm{~J} / \mathrm{cm}^{2}$ & $9.40(0.31)$ & 0.59 & 70.84 \\
\hline & & $90 \mathrm{~J} / \mathrm{cm}^{2}$ & $8.93(0.21)$ & 1.05 & 90.53 \\
\hline & \multirow[t]{3}{*}{$312 \mu \mathrm{M}$} & $30 \mathrm{~J} / \mathrm{cm}^{2}$ & $9.68(0.02)$ & 0.31 & 51.09 \\
\hline & & $60 \mathrm{~J} / \mathrm{cm}^{2}$ & $8.31(0.00)$ & 1.69 & 97.96 \\
\hline & & $90 \mathrm{~J} / \mathrm{cm}^{2}$ & $0.00(0.00)$ & 9.98 & 100 \\
\hline \multirow[t]{9}{*}{ Propionibacterium acnes } & \multirow[t]{3}{*}{$39 \mu \mathrm{M}$} & $30 \mathrm{~J} / \mathrm{cm}^{2}$ & $8.12(0.17)$ & 0.00 & 0.00 \\
\hline & & $60 \mathrm{~J} / \mathrm{cm}^{2}$ & $8.09(0.24)$ & 0.11 & 26.65 \\
\hline & & $90 \mathrm{~J} / \mathrm{cm}^{2}$ & $7.84(0.14)$ & 0.36 & 55.57 \\
\hline & \multirow[t]{3}{*}{$78 \mu \mathrm{M}$} & $30 \mathrm{~J} / \mathrm{cm}^{2}$ & $8.12(0.16)$ & 0.08 & 24.72 \\
\hline & & $60 \mathrm{~J} / \mathrm{cm}^{2}$ & $8.07(0.15)$ & 0.04 & 25.82 \\
\hline & & $90 \mathrm{~J} / \mathrm{cm}^{2}$ & $7.65(0.17)$ & 0.55 & 70.78 \\
\hline & \multirow[t]{3}{*}{$156 \mu \mathrm{M}$} & $30 \mathrm{~J} / \mathrm{cm}^{2}$ & $8.09(0.18)$ & 0.11 & 28.57 \\
\hline & & $60 \mathrm{~J} / \mathrm{cm}^{2}$ & $7.14(0.33)$ & 0.97 & 89.59 \\
\hline & & $90 \mathrm{~J} / \mathrm{cm}^{2}$ & $0.00(0.00)$ & 8.20 & 100 \\
\hline
\end{tabular}

\footnotetext{
a Compared to control.
}

light dose combinations resulted in complete $P$. acnes elimination.

Table 3 shows the results obtained from aPDT employing methylene blue as the PS. P. acnes was less susceptible to aPDT with MB compared with the other photosensitizers, but remained more sensitive than $E$. faecalis, which is evidenced by the concentration of MB required to completely eliminate both strains, using the same light dose: $P$. acnes colony forming units (CFU) were eliminated with half the concentration $(156 \mu \mathrm{M})$ necessary to eliminate $E$. faecalis $\mathrm{CFU}(312 \mu \mathrm{M})$.

\subsection{Photosensitizer Uptake}

The difference in susceptibility observed between the two strains could be a result of differential uptake of the photosensitizers; therefore, the ability to uptake each PS was investigated for both strains, using two concentrations of each photosensitizer. As can be seen in Fig. 2, P. acnes (averages around $8 \times 10^{-9}$ ) uptakes 80 times more PS than E. faecalis (averages around $1 \times 10^{-10}$ ), evidencing that the higher susceptibility of $P$. acnes to aPDT is a result of superior accumulation of PS molecules inside the cell, which directly affects the concentration of ROS generated in lethal locations within the bacterium. Moreover, increasing the initial concentration of the PS administered to the bacteria does not affect the concentration of PS internalized, revealing that (i) there is a saturation of the system and (ii) that the light dose plays a major role in the success of PDT.

\section{Discussion}

Bacteria composing the Enterococcus genera are related to the majority of hospital infections, being the third most isolated nosocomial pathogen. Although several species might be related to diseases, most enterococcal infections in humans are caused by E. faecalis [35,36], including endodontic, urinary tract, and wound infections, endocarditis, and bacteremia [37]. Infections caused by vancomycin-resistant $E$. faecalis are of particular concern because the genes conferring 

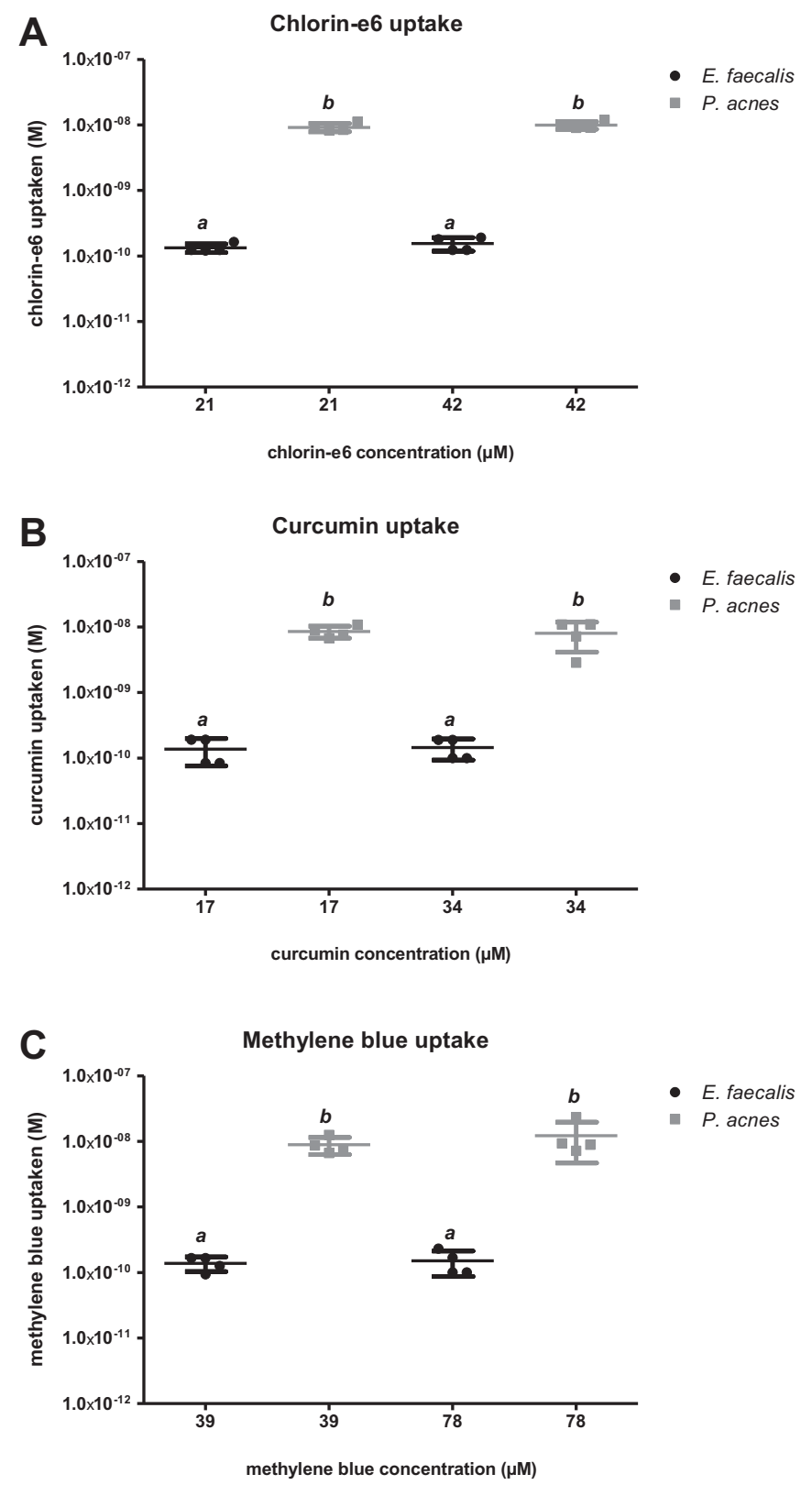

Fig. 2. Photosensitizer uptake assays. Standardized suspensions of Enterococcus faecalis or Propionibacterium acnes were incubated with chlorin-e6 (21 or $42 \mu \mathrm{M}$; A), curcumin (17 or $34 \mu \mathrm{M}$; B) methylene blue ( 39 or $78 \mu \mathrm{M}$; C), for $5 \mathrm{~min}$ in the dark. The lines inside represent the averages with standard deviation. Four independent assays $(n=12)$. Different letters note statistical difference among groups. One-way ANOVA with Tukey post-hoc. MB: methylene blue; Ce6: chlorin-e6; CUR: curcumin. (For interpretation of the references to colour in this figure legend, the reader is referred to the web version of this article.)

it resistance are located in mobile genetic elements, such as plasmids and transposons, making the spread of resistance to other strains especially easy [38].

$P$. acnes, by its turn, is an opportunistic pathogen highlighted in the literature by being considered the main causative microorganism of acne vulgaris [39], a chronic skin disease that can result in disfiguring scars, usually accompanied by severe psychological impact on patients [40]. To a minor extent, $P$. acnes is also related to other infections, including osteomyelitis, endophthalmitis, endocarditis, joint prostheses infections, and endodontic infections [41-44]. In recent years, reports revealing increasing antimicrobial resistance of $P$. acnes to antimicrobials used for the treatment of acne vulgaris have grown in number [45].

The clinical relevance of both strains, together with their increasing resistance $o$ antimicrobials, grounds the importance of pursuing new therapeutic strategies to manage infections caused by them. Within the limitations of this in vitro study, aPDT mediated by the three PS was effective in eliminating $E$. faecalis and P. acnes. Although both bacteria present the same basic cell wall architectures, we observed that the parameters necessary to reduce the microbial load were very different between the two species. P. acnes was lethally susceptible to all combinations of light dose and Ce6 or CUR concentrations. To completely eliminate $E$. faecalis, however, it was necessary to apply a Ce6 concentration 16-fold higher and a light dose 18-fold higher; for CUR-PDT, E. faecalis required almost 5 times more CUR and 8 times more light energy. Those results evidenced that $P$. acnes is particularly more susceptible to CUR-PDT and Ce6-PDT than E. faecalis. Regarding MB-PDT, $E$. faecalis required only twice the concentration of $\mathrm{MB}$ than $P$. acnes, demonstrating that both strains have similar susceptibility to this cationic PS.

As our results revealed, $P$. acnes internalizes almost 100 times more PS than E. faecalis, regardless the molecule or its administered concentration. Since ROS have a short radius of action ( $~ 2 \mathrm{~nm}$ in average), the site of generation of those species once the PS is activated by the light is a key factor for the success of PDT, which means that the specific localization of the molecule inside the cell (i.e., associated with DNA, proteins or the cytoplasmic membrane) directly influences the efficiency of a photosensitizer and is strictly related to its chemical nature $[46,47]$. Therefore, even though all three PS were internalized at similar rates within one strain, they presented different efficiency (Ce6 > CUR > MB) most likely due to their distinct affinity to intracellular molecules.

\section{Conclusion}

According to the methodology employed in this in vitro study, aPDT mediated by curcumin, chlorin-e6 or methylene blue is an effective alternative to eliminate both Enterococcus faecalis and Propionibacterium acnes. $P$. acnes showed remarkably higher susceptibility to aPDT when compared to $E$. faecalis, which was revealed to be a result of differences in PS internalization by the two strains. Our results evidence that susceptibility to aPDT cannot be predicted solely based on the cell wall structures of bacteria.

\section{Author's Disclosure of Potential Conflicts of Interest}

The authors declare that there are no potential conflicts of interest.

\section{Acknowledgments}

This work received funding from Fundação de Amparo à Pesquisa do Estado de São Paulo - FAPESP (Grant \# 2016/05345-4, Regular Research Funding of CR Fontana; grant \#2014/24581-5, doctorate fellowship of LM de Freitas; grant \# 2013/07276, CEPOF; and grant \# 2015/21110-4, K. T. O regular funding), CNPq-Master's degree fellowship of SR de Annunzio. We would like to thank Programa de Apoio ao Desenvolvimento Científico -Faculdade de Ciências Farmacêuticas UNESP (PADC-FCF) for additional financial support.

\section{References}

[1] S.T. Cole, Who will develop new antibacterial agents? Philos. Trans. R. Soc. Lond. Ser. B Biol. Sci. 369 (2014) 597-602, http://dx.doi.org/10.1098/rstb.2013.0430.

[2] T.G. Denis, et al., All you need is light: antimicrobial photoinactivation as an evolving and emerging discovery strategy against infectious disease, Virulence 2 (2011) 509-520, http://dx.doi.org/10.4161/viru.2.6.17889.

[3] M. Kim, H.Y. Jung, H.J. Park, Topical PDT in the treatment of benign skin diseases: principles and new applications, Int. J. Mol. Sci. 16 (2015) 23259-23278, http:// dx.doi.org/10.3390/ijms161023259. 
[4] D.E.J.G.J. Dolmans, D. Fukumura, K.J. Rakesh, Photodynamic therapy for cancer, Nat. Rev. Cancer 3 (2003) 380-387, http://dx.doi.org/10.1038/nrc1070.

[5] A.D.H. Machado, Photodynamic therapy: principles, potential of application and perspectives, Quim Nova 23 (2000) 237-243, http://dx.doi.org/10.1590/S010040422000000200015.

[6] G.B. Kharkwal, et al., Photodynamic therapy for infections: clinical applications, Lasers Surg. Med. 43 (2011) 755-767, http://dx.doi.org/10.1002/2fism.21080.

[7] M.S. Ribeiro, D.F.T. Silva, S.C. Núnez, D.M. Zezell, Treaty of Aesthetic Medicine, second ed., (2011) (São Paulo, Brazil).

[8] C.H. Sibata, V.C. Colussi, N.L. Oleinick, T.J. Kinsella, Photodynamic therapy: a new concept in medical treatment, Braz. J. Med. Biol. Res. 33 (2000) 869-880, http:// dx.doi.org/10.1590/S0100-879X2000000800002.

[9] S.K. Pushpan, et al., Porphyrins in photodynamic therapy - a search for ideal photosensitizers, Curr. Med. Chem. Anti-Cancer Agents 2 (2002) 187-207, http:// dx.doi.org/10.2174/1568011023354137.

[10] J.R. Perussi, Photodynamic inactivation of microorganisms, Quim Nova 30 (2007) 988, http://dx.doi.org/10.1590/S0100-40422007000400039.

[11] C.R. Fontana, et al., The antibacterial effect of photodynamic therapy in dental plaque-derived biofilms, J. Periodontal Res. 44 (2009) 751-759, http://dx.doi.org/ 10.1111/j.1600-0765.2008.01187.x.

[12] H. Ghanbari, et al., Synergic phototoxic effect of visible light or gallium-arsenide laser in the presence of different photo-sensitizers on Porphyromonas gingivalis and Fusobacterium nucleatum, Dent. Res. J. 12 (2015) 323-330, http://dx.doi.org/10. 4103/1735-3327.161432.

[13] M.R. Ronqui, et al., Synergistic antimicrobial effect of photodynamic therapy and ciprofloxacin, J. Photochem. Photobiol. B 158 (2016) 122-129, http://dx.doi.org/ 10.1016/j.jphotobiol.2016.02.036.

[14] M. Pourhajibagher, et al., Evaluation of photo-activated disinfection effectiveness with methylene blue against Porphyromonas gingivalis involved in endodontic infection: an in vitro study, Photodiagn. Photodyn. Ther. 16 (2016) 132-135, http:// dx.doi.org/10.1016/j.pdpdt.2016.09.008.

[15] E.M. Bruzell, E. Morisback, H.H. Tonnesen, Studies on curcumina and curcuminoids. XXIX. Photoinduced cytotoxicity of curcumin in selected aqueous preparations, Photochem. Photobiol. Sci. 4 (2005) 523-530, http://dx.doi.org/10.1039/ B503397G.

[16] L.N. Dovigo, et al., Investigation of photodynamic effects of curcumin against Candida albicans, Photochem. Photobiol. 87 (2011) 895-903, http://dx.doi.org/10. 1111/j.1751-1097.2011.00937.x.

[17] F. Cieplik, L. Tabenski, W. Buchalla, T. Maisch, Antimicrobial photodynamic therapy for inactivation of biofilms formed by oral key pathogens, Front. Microbiol. 5 (2014) 1-4, http://dx.doi.org/10.3389/fmicb.2014.00405.

[18] J.P. Tardivo, et al., Methylene blue in photodynamic therapy: from basic mechanisms to clinical applications, Photodiagn. Photodyn. Ther. 2 (2005) 175-191, http://dx.doi.org/10.1016/S1572-1000(05)00097-9.

[19] L.M. Moreira, J.P. Lyon, A.P. Romani, D. Severino, M.R. Rodrigues, Phenotiazinium dyes as photosensitizers (ps) in photodynamic therapy (pdt): spectroscopic properties and photochemical mechanisms, in: H.P.M. de Oliveira (Ed.), Advanced Aspects of Spectroscopy, InTech, Brazil, 2012, pp. 393-420.

[20] B. Grimm, R.J. Porra, W.R. Diger, H. Scheers (Ed.), Chlorophylls and Bacteriochlorophylls: Biochemistry, Biophysics, Functions and Applications, H. Springer, The Netherlands, 2006, pp. 1-26.

[21] L. Huang, et al., Photodynamic inactivation of bacteria using Polyethylenimine-Chlorin(e6) conjugates: effect of polymer molecular weight, substitution ratio of Chlorin(e6) and pH, Lasers Surg. Med. 43 (2011) 313-323, http://dx.doi.org/10.1002/lsm.21056.

[22] K.T.D. Oliveira, et al., Chlorins: natural sources, synthetic developments and main applications, Curr. Org. Synth. 11 (2014) 42-58, http://dx.doi.org/10.2174/ 15701794113106660085.

[23] P. Diogo, et al., Antimicrobial photodynamic therapy against endodontic Enterococcus faecalis and Candida albicans mono and mixed biofilms in the presence of photosensitizers: a comparative study with classical endodontic Irrigants, Front. Microbiol. 8 (2017), http://dx.doi.org/10.3389/fmicb.2017.00498.

[24] M.R. Hamblin, T. Hasan, Photodynamic therapy: a new antimicrobial approach to infectious disease? Photochem. Photobiol. Sci. 3 (2004) 436-450, http://dx.doi. org/10.1039/b311900a.

[25] T. Maisch, et al., Photodynamic effects of novel XF porphyrin derivatives on prokaryotic and eukaryotic cells, Antimicrob. Agents Chemother. 49 (2005) 1542-1552, http://dx.doi.org/10.1128/AAC.49.4.1542-1552.2005.

[26] T. Demidova, M.R. Hamblin, Effect of cell-photosensitizer binding and cell density on microbial photoinactivation, Antimicrob. Agents Chemother. 49 (2005)
2329-2335, http://dx.doi.org/10.1128/AAC.49.6.2329-2335.2005.

[27] J.Y. Nagata, et al., Antibacterial photodynamic therapy for dental caries: evaluation of the photosensitizers used and light source properties, Photodiagn. Photodyn. Ther. 9 (2012) 122-131, http://dx.doi.org/10.1016/j.pdpdt.2011.11.006.

[28] G. Jori, et al., Photodynamic therapy in the treatment of microbial infections: basic principles and perspective applications, Lasers Surg. Med. 38 (2006) 468-481, http://dx.doi.org/10.1002/lsm.20361.

[29] T. Tsai, et al., Improved photodynamic inactivation of gram-positive bacteria using hematoporphyrin encapsulated in liposomes and micelles, Lasers Surg. Med. 41 (2009) 316-322, http://dx.doi.org/10.1002/lsm.20754.

[30] N. Kashef, Y.S. Borgheu, G.E. Djavid, Photodynamic effect of hypericin on the microorganisms and primary human fibroblasts, Photodiagn. Photodyn. Ther. 10 (2013) 150-155, http://dx.doi.org/10.1016/j.pdpdt.2012.11.007.

[31] Y. Zhang, H.C. Ertl, The effect of adjuvanting cancer vaccines with herpes simplex virus glycoprotein D on melanoma-driven CD8 + T cell exhaustion, J. Immunol. 193 (2014) 1836-1846, http://dx.doi.org/10.4049/jimmunol.1302029.

[32] M.P. Uliana, et al., Photobiological characteristics of chlorophyll a derivatives as microbial PDT agents, Photochem. Photobiol. Sci. 13 (2014) 1137-1145, http://dx. doi.org/10.1039/c3pp50376c.

[33] C.C.C. Vargas, L.D.C. Alves, T.J. Brocksom, K.T.D. Oliveira, Combining batch and continuous flow setups in the end-to-end synthesis of naturally occurring curcuminoids, react, Chem. Eng. 00 (2016) 1-3, http://dx.doi.org/10.1039/ C6RE00207B.

[34] W. Wichitnithad, U. Nimmannit, P.S. Callery, P. Rojsitthisak, Effects of different carboxylic Ester spacers on chemical stability, release characteristics, and anticancer activity of mono-PEGylated curcumin conjugates, J. Pharm. Sci. 100 (2011) 5206-5218, http://dx.doi.org/10.1002/jps.22716.

[35] A.I. Hidron, et al., NHSN annual update: antimicrobial-resistant pathogens associated with healthcare-associated infections: annual summary of data reported to the National Healthcare Safety Network at the Centers for Disease Control and Prevention, 2006-2007, Infect. Control Hosp. Epidemiol. 29 (2008) 996-1011, http://dx.doi.org/10.1086/591861.

[36] A. Sood, et al., Potential for interactions between dietary supplements and prescription medications, Am. J. Med. 121 (2008) 207-211, http://dx.doi.org/10 1016/j.amjmed.2007.11.014.

[37] L. Andrew, et al., Enterococcus faecalis tropism for the kidneys in the urinary tract of C57BL/6J mice, Infect. Immun. 73 (2005) 2461-2468, http://dx.doi.org/10.1128/ IAI.73.4.2461-2468.2005.

[38] P. Courvalin, Vancomycin resistance in gram-positive cocci, Clin. Infect. Dis. 42 (2006) 25-34, http://dx.doi.org/10.1086/491711.

[39] C. Dessinioti, A.D. Katsambas, The role of Propionibacterium acnes in acne pathogenesis: facts and controversies, Clin. Dermatol. 28 (2010) 2-7, http://dx.doi.org/ 10.1016/j.clindermatol.2009.03.012.

[40] S.C. Kellett, D.J. Gawkrodge, The psychological and emotional impact of acne and the effect of treatment with isotretinoin, Br. J. Dermatol. 140 (1999) 273-282 10233222.

[41] T. Nakatsuji, et al., Bioengineering a humanized acne microenvironment model: proteomics analysis of host responses to Propionibacterium acnes infection in vivo, Proteomics 8 (2008) 3406-3415, http://dx.doi.org/10.1002/pmic.200800044.

[42] A. Holmberg, et al., Biofilm formation by Propionibacterium acnes is a characteristic of invasive isolates, Clin. Microbiol. Infect. 15 (2009) 787-795, http://dx.doi.org/ 10.1111/j.1469-0691.2009.02747.x.

[43] T. Herren, M.A. Middendorp, R. Zbinden, Quantification of the antibody response to Propionibacterium acnes in a patient with prosthetic valve endocarditis: - a case report, BMC Infect. Dis. 29 (2016) 1-5, http://dx.doi.org/10.1186/s12879-0161522-2.

[44] S.A. Niazi, et al., Propionibacterium acnes among the microbiota of primary endodontic infections with and without intraoral communication, Clin Oral Investig 9 (2016) 2149-2160, http://dx.doi.org/10.1007/s00784-016-1739-x.

[45] G.G. Aubin, M.E. Portillo, A. Trampuz, S. Corvec, Propionibacterium acnes, an emerging pathogen: from acne toimplant-infections, from phylotype to resistance, Med. Mal. Infect. 44 (2014) 241-250, http://dx.doi.org/10.1016/j.medmal.2014. 02.004 .

[46] S. George, M.R. Hamblin, A. Kishen, Uptake pathways of anionic and cationic photo-sensitizers into bacteria, Photochem. Photobiol. Sci. 8 (2009) 788-795, http://dx.doi.org/10.1039/b809624d.

[47] C.S. Oliveira, et al., Major determinants of photoinduced cell death: subcellular localization versus photosensitization efficiency, Free Radic. Biol. Med. 51 (2011) 824-833, http://dx.doi.org/10.1016/j.freeradbiomed.2011.05.023. 